\title{
AS MULHERES SÃO HUMANAS? ${ }^{1}$
}

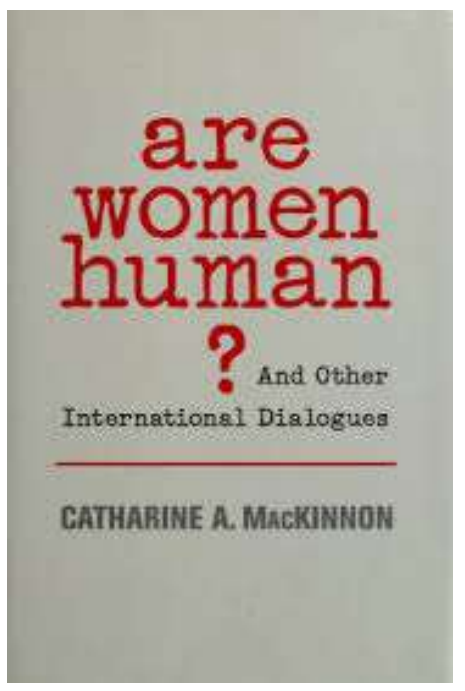

Catharine Mackinnon*

\section{As Mulheres são Humanas? ${ }^{2}$}

\footnotetext{
${ }^{1}$ I. “Are Women Human?” from ARE WOMEN HUMAN? AND OTHER INTERNATIONAL DIALOGUES, published by The Belknap Press of Harvard University Press, C 2006 by Catharine A. MacKinnon.
}

II. A tradução e publicação deste artigo de Catharine MacKinnon foi possível graças à permissão concedida à revista VirtuaJus pelo seu agente, Jason Christian (for Catharine MacKinnon). Nossos sinceros agradecimentos à Professora Catharine MacKinnon pela possibilidade de publicação de seu texto em português no presente volume da revista Virtuajus da Faculdade Mineira de Direito da Pontifícia Universidade Católica de Minas Gerais, Brasil. Our sincere thanks to Professor Catharine MacKinnon for her cordiality.

III. Tradução do texto por Magda Guadalupe dos Santos. Professora doutora da PUC Minas e da FaE. UEMG. Pesquisadora de Filosofia e Teorias Feministas.

* Catharine A. MacKinnon é advogada e professora da Faculdade de Direito na Universidade de Michigan. De 2008 a 2012 foi a primeira Consultora Especial de Gênero da Promotoria do Tribunal Penal Internacional. Ela é professora visitante na Harvard Law School desde 2009. Seus livros, traduzidos para vários idiomas, incluem Sexual Harassment of Working Women (1979), Feminism Unmodified (1987), Toward a Feminist Theory of the State (1989), Only Words (1993), Women's Lives, Men's Laws (2005), Are Women Human? (2006), Sex Equality (2016) e Butterfly Politics (2017). Seu incansável trabalho em prol da igualdade de direitos entre os gêneros tornou possível o reconhecimento, nos EUA e no mundo, da ilegalidade do assédio sexual no emprego e na educação. No final da Guerra do Kosovo, ocorrida na década de 1990, representou mulheres bósnias sobreviventes de atrocidades sexuais sérvias e conseguiu estabelecer, em tribunal internacional, o reconhecimento legal de estupro como crime no nível do genocídio. Ela trabalha ainda com a ERA Coalition e a Coalition Against Trafficking in Women $(C A T W)$. Nos últimos anos tem-se dedicado ao estudo dos danos causados às mulheres pela violência pornográfica.

\footnotetext{
${ }^{2}$ Essa análise foi publicada originalmente em Reflexões sobre a Declaração Universal dos Direitos Humanos 171
} (Barend van der Heijden e Bahia Tahzib-Lie, Orgs., 1999). 
A Declaração Universal dos Direitos Humanos define o que é um ser humano. Em 1948, ela afirmou ao mundo quais os direitos que uma pessoa tem enquanto pessoa. Já se passaram cinquenta anos. As mulheres já são humanas?

Se as mulheres fossem humanas, seríamos uma carga transportada da Tailândia, em contêineres, para os bordéis de Nova York? Seríamos escravas sexuais e reprodutivas? Seríamos criadas trabalhando sem pagamento durante a nossa vida inteira, queimadas quando o dinheiro do nosso dote não fosse suficiente ou quando os homens se cansassem de nós, morreríamos de fome, como viúvas, quando nossos maridos morressem (caso sobrevivêssemos à pira funerária), seríamos vendidas por sexo, porque não temos valor para nada mais?

Seríamos vendidas em casamento a sacerdotes para expiar os pecados de nossa família ou melhorar as perspectivas terrenas de nossa família? Seríamos, quando autorizadas a trabalhar por um salário, obrigadas a trabalhar em empregos servis e ser exploradas quase a nível da inanição? Nossos órgãos genitais seriam cortados para nos "purificar" (nossas partes do corpo são sujas?), para nos controlar, para nos marcar e definir nossas culturas? Seríamos traficadas como coisas para uso sexual e de entretenimento em todo o mundo, por qualquer modo que a tecnologia atual tornar possível? Seríamos impedidas de aprender a ler e escrever?

Se as mulheres fossem humanas, teríamos tão pouca voz nas deliberações públicas e no governo dos países em que vivemos? Seríamos escondidas por detrás de véus e presas em casas e seríamos apedrejadas e levaríamos tiro por recusarmos? Seríamos espancadas quase até a morte, e mesmo até a morte, por homens de quem somos próximas? Seríamos molestadas sexualmente em nossas famílias? Seríamos estupradas em genocídio, para aterrorizar, excluir e destruir nossas comunidades étnicas, e estupradas novamente naquela guerra não declarada que ocorre todos os dias em todos os países do mundo, no que é chamado de tempo de paz?

Se as mulheres fossem humanas, nossa violação seria desfrutada pelos nossos violadores? E, se fôssemos humanas, quando essas coisas acontecessem, praticamente nada seria feito a este respeito?

É preciso muita imaginação - e um foco determinado e obcecado pelas exceções das margens privilegiadas - para ver uma mulher real nas majestosas garantias da Declaração Universal sobre "o direito de todos". Depois de mais de meio século, qual a parte de "todos" 
não nos representa? A linguagem reverberante do Artigo 1 nos encoraja a "agir um para com o outro em espírito de fraternidade". ${ }^{3}$

Devemos ser antes homens para que seu espírito nos inclua? Para que isso seja visto como bastante literal, se todos fôssemos obrigadas a "agir uns em relação aos outros em espírito de irmandade", os homens saberiam que isso também se referiria a eles?

O Artigo $23,{ }^{4}$ de forma encorajadora, prevê um pagamento justo para "todos que

trabalham". ${ }^{5}$ Ele continua afirmando que isso garante uma vida de dignidade humana para "si mesmo e sua família". As mulheres, em nenhum lugar, são pagas pelo trabalho que (nós) realizamos em nossas próprias famílias, porque não somos "todos" ou porque o que fazemos não é "trabalho", ou apenas porque não somos "ele"?

As mulheres não têm família, ou é que as mulheres não têm família sem "ele"? Se o alguém que não é pago de forma alguma, muito menos com a "remuneração justa e favorável"

\footnotetext{
${ }^{3} \mathrm{O}$ artigo 1. e o de no. 23 da Declaração Universal dos Direitos (UDHR) foram acrescidos a esta edição pela tradutora para facilitar o entendimento do texto.

Article 1. The Universal Declaration of Human Rights (UDHR)

All human beings are born free and equal in dignity and rights. They are endowed with reason and conscience and should act towards one another in a spirit of brotherhood.
}

Todos os seres humanos nascem livres e iguais em dignidade e direitos. Eles são dotados de razão e consciência e devem agir uns com os outros com espírito de fraternidade.

\section{${ }^{4}$ Article 23. The Universal Declaration of Human Rights (UDHR)}

(1) Everyone has the right to work, to free choice of employment, to just and favourable conditions of work and to protection against unemployment.

(2) Everyone, without any discrimination, has the right to equal pay for equal work.

(3) Everyone who works has the right to just and favourable remuneration ensuring for himself and his family an existence worthy of human dignity, and supplemented, if necessary, by other means of social protection.

(4) Everyone has the right to form and to join trade unions for the protection of his interests.

(1) Todo ser humano tem direito ao trabalho, à livre escolha de emprego, a condições justas e favoráveis de trabalho e à proteção contra o desemprego.

(2) Todo ser humano, sem qualquer discriminação, tem direito a igual remuneração por igual trabalho.

(3) Todo ser humano que trabalha tem direito a uma remuneração justa e satisfatória, que lhe assegure, assim como à sua família, uma existência compatível com a dignidade humana, complementada, se necessário, por outros meios de proteção social. ,

(4) Todo ser humano tem direito a organizar sindicatos e a neles ingressar para proteção de seus interesses.

${ }^{5}$ Nota da tradutora. A autora traz aqui um jogo de linguagem. No original está escrito "[e]evryone who woks", podendo-se enfatizar apenas "veryone" ou very one who works", como aquele que trabalha. 
garantida, é também o mesmo alguém que, na vida real, é frequentemente responsável pelo sustento de sua família, quando ela é privada de fornecer a sua família "uma existência condigna de ser humano", ela não é humana?

E agora que "todos" têm direito de "participar do governo de seu país", desde a promulgação da Declaração Universal, por que a maior parte dos governos ainda é exercida principalmente por homens? As mulheres estão caladas nos corredores do estado porque não temos voz humana?

Um documento que previsse a formação de sindicatos e "férias periódicas remuneradas" poderia em algum momento acrescentar algo específico sobre as mulheres que não fosse apenas a "Maternidade", que é mais reverenciada do que prevista.

Se as mulheres fossem humanas neste documento, a violência doméstica, a violação sexual, desde o nascimento até a morte, incluindo a prostituição e a pornografia, a objetivação sexual sistemática e a depreciação de mulheres e meninas, seriam simplesmente excluídas da linguagem explicita? Sendo reconhecida, a discriminação sexual está proibida. Mas como ela pode ter sido proibida há tanto tempo, mesmo que só como aspiração, e o fim de todas essas condições ainda não ser concretamente imaginado como parte do que um ser humano, como humano, tem direito?

Por que o direito das mulheres de pôr fim a essas condições ainda é debatido abertamente com base em direitos culturais, direitos de fala, direitos religiosos, liberdade sexual, livre mercado - como se as mulheres fossem significantes sociais, discursos de cafetões, fetiches sagrados ou sexuais, recursos naturais, bens móveis, tudo, menos seres humanos?

As omissões na Declaração Universal não são meramente semânticas. Ser mulher “ainda não é uma designação para um modo de ser humano", nem mesmo neste que é o mais visionário dos documentos de direitos humanos. Se medirmos a realidade da situação das mulheres, em toda sua diversidade, frente às garantias da Declaração Universal, não apenas as mulheres não têm os direitos que ela garante - a maioria dos homens do mundo também não -, mas é difícil enxergar, em sua visão da humanidade, a figura de uma mulher.

As mulheres têm necessidade de um estatuto humano pleno na realidade social. Para isso, a Declaração Universal dos Direitos Humanos tinha de considerar os modos como as mulheres são efetivamente privadas dos direitos humanos como uma privação de humanidade. Para que o sonho glorioso da Declaração Universal se torne realidade, para que os direitos humanos sejam universais, tanto a realidade que ela desafia quanto o padrão que ela estabelece precisam mudar. 
Quando as mulheres serão humanas? Quando?"

Notas do livro de Catharine MacKinnon. Are Women Human? And Other International Dialogues. Capítulo IV.

\section{As Mulheres são Humanas?}

1. A Declaração Universal dos Direitos Humanos, G. A. Res. 217, U.N. GAOR, $3^{\mathrm{a}}$. Sess., em 72-76, U.N. Doc. A / 810 (1948). Todas as citações da Declaração Universal neste ensaio podem ser encontradas aqui.

2. Para dados que sustentam todas as declarações sobre violência contra as mulheres nesta análise, consulte Radhika Coomaraswamy, Relatório apresentado pela Relatora Especial sobre Violência contra Mulheres, Suas Causas e Consequências, Comissão de Direitos Humanos, 50 a Sessão., Item da Agenda 11 (a), Doc. Da ONU. E / CN.4 / 1995/42 (1995); Radhika Coomaraswamy, Relatório do Relator Especial sobre Violência contra as Mulheres, Suas Causas e Consequências, ONU. ESCOR Hum. Rts. Comm'n, 52. Sess., Prov. Item 9 (a) da agenda, Doc. Da ONU E / CN.4 / 1996/53 (1996); Radhika Coomaraswamy, Relatório, ONU ESCOR Hum. Rts. Reunião, 53ª Sessão, Prov. Item 9 (a) da agenda, Doc. Da ONU E / CN.4 / 1997/47 (1997).

3. Ver Tráfico de Mulheres e Meninas (Traffic in Women and Girls), Resolução da Subcomissão de Direitos Humanos 2002/51 E / CN.4 / RES / 2002/51 (23 de abril de 2002). O Departamento de Estado dos EUA estima que cerca de 800.000 pessoas são traficadas internacionalmente anualmente, a maioria das quais são mulheres e crianças. Relatório 7 de Tráfico de Pessoas 7 (junho de 2003).

4. A maioria dos analfabetos do mundo são mulheres. Ver UNESCO, Statistical Yearbook 1997 2-6 tbl. 2-2 (estimando que $28,8 \%$ das mulheres e $16,3 \%$ dos homens do mundo são analfabetos).

5. Ver Interparliamentary Union, Women in Parliaments, 1945-1995: A World Statistical Study (1995).

6. Ver "Mulheres 11 de setembro: Repensando o Direito Internacional do Conflito", abaixo, no $\mathrm{n}^{\circ} 25$ abaixo, para a discussão deste conceito.

7. Richard Rorty, "Feminism and Pragmatism," 30'. Michigan Quarterly Review 231, 234 (Primavera de 1991) (“O ponto central de MacKinnon, conforme eu a li, é que 'uma mulher' ainda não é a expressão de uma forma de ser humano"). 